Article

\title{
Psychological Processes and Personality Factors for an Appropriate Tsunami Evacuation
}

\author{
Motoaki Sugiura ${ }^{1,2, * \mathbb{D}}$, Shosuke Sato ${ }^{1}$, Rui Nouchi ${ }^{2}$, Akio Honda ${ }^{3}$, Ryo Ishibashi ${ }^{4}$, \\ Tsuneyuki Abe ${ }^{5}$, Toshiaki Muramoto ${ }^{1}$ and Fumihiko Imamura ${ }^{1}$ (D) \\ 1 International Research Institute of Disaster Science, Tohoku University, Sendai 980-8572, Japan \\ 2 Institute of Development, Aging and Cancer, Tohoku University, Sendai 980-8575, Japan \\ 3 Faculty of Informatics, Shizuoka Institute of Science and Technology, Fukuroi 437-8555, Japan \\ 4 Smart-Aging Research Center, Tohoku University, Sendai 980-8575, Japan \\ 5 Graduate School of Arts and Letters, Tohoku University, Sendai 980-8576, Japan \\ * Correspondence: sugiura@tohoku.ac.jp
}

Received: 15 June 2019; Accepted: 22 July 2019; Published: 25 July 2019

\begin{abstract}
Although various factors related to the environment (perception of earthquake and warning) and knowledge (oral history and scientific knowledge) affect individual differences in evacuation behavior before a tsunami, the roles of psychological processes and personality factors in such relationships are poorly understood. We addressed this research gap by applying hierarchical regression analyses to survey data from survivors of the 2011 Tohoku earthquake and tsunami disaster. Previously-known contributions of environmental and knowledge factors were mostly replaced by the perception of a tsunami risk and threat, and these background factors were shown to facilitate these psychological processes. Several personality factors directly contributed to voluntary evacuation, particularly leadership and active well-being in the Power to Live scale, and extraversion in the Big Five scale. Overall, these results seem to indicate the need for formulating two independent targets when developing measures to enhance appropriate tsunami evacuation. Facilitation of the perception of a tsunami risk and threat may basically be pursued by developing existing approaches. Addressing the relevant personality factors may be done in a broader context of disaster or general education and sociocultural activities.
\end{abstract}

Keywords: earthquake; education; normalcy bias; personality; risk perception; threat perception; tsunami evacuation; warning

\section{Introduction}

A massive tsunami event is often preceded by an environmental cue, such as an earthquake, or by an official warning, which allows people to protect themselves by evacuating to high ground. Nevertheless, the response varies across individuals [1-6]. In an early quantitative survey of the 1960 Hawaiian tsunami, only 41\% of residents who recognized the warning responded [7]. In the recent 2011 Tohoku (or Great East Japan) earthquake and tsunami disaster, which we address in this study, only $57 \%$ of residents evacuated immediately, even after experiencing the severe earthquake and hearing the rapid warning [8]. The importance of educational measures to promote rapid evacuation has been increasingly emphasized, given the limited effectiveness of structural countermeasures for a massive tsunami $[9,10]$.

Psychological processes seem key to understanding such individual differences, but remain poorly understood. The importance of the perception of a hazardous risk and threat has repeatedly been suggested for evacuation behavior in the event of a tsunami [1-6], but empirical data are missing. In addition, although dissociable contributions of risk and threat perception have been demonstrated for 
other types of disasters, such as hurricanes, tornadoes, earthquakes, and volcanoes [11-15], the issue is yet to be addressed for a tsunami. Understanding the likelihood of a hazard (risk perception) is a cognitive process considered less effective in triggering a protective response than affective responses (e.g., fear, worry, or preoccupation) or the expectation of personal consequences of a hazard (threat perception). This concept is not necessarily applicable to a tsunami evacuation, given its unique characteristics, including in terms of the time period and methods available [6]. The contribution of a mnemonic process to the decision to evacuate is also of interest. Empirical surveys have demonstrated a positive association between past experience of a tsunami [7] and evacuation drills [16,17] with an adaptive response. However, it has yet to be examined whether these experiences are remembered in the face of a cue of an impending tsunami and can promote evacuation.

Furthermore, it is important to know whether these psychological processes mediate the associations between various background factors and evacuation behaviors. Qualitative studies have suggested the importance of knowledge (passed down orally and accrued at school) in evacuation from a tsunami [1-3,5]. In addition, various other background factors, such as demographic (age and sex) and environmental (perception of the severity of an earthquake and warning) factors, have been empirically demonstrated to be associated $[6,16]$. With respect to the dissociable contributions of risk and threat perceptions, various sociocultural, environmental, and demographic factors are thought to explain this dissociation [11,12]. If a relationship can be found between a key psychological process and such a factor, this would enable a causal explanation for the association. Furthermore, with regard to the identification of environmental or knowledge factors, the process may lead to an index for successful environmental or educational intervention for disaster mitigation.

Personality traits are potentially predictive of adaptive evacuation. There are major individual differences in psychological and behavioral responses to an environment, which are typically measured using self-rated questionnaires. These traits appear to be relevant to the psychological processes described herein and may be a good target for educational interventions, but few studies related to disasters have explored this. Although some have discussed the issue $[7,18]$, empirical findings have been limited: only the "locus of control" [19] has been discussed, and only in terms of tornado or hurricane disasters $[20,21]$. This line of research appears promising, given the demonstrated relationship between scores on the Big Five basic personality dimensions and the perceptions of various types of risky social behaviors [22]. We previously explored survival-oriented personality factors (Power to Live scale) in a broad context related to the 2011 Tohoku earthquake and tsunami disaster and found that of the eight factors identified, emotion regulation, leadership, and problem solving were associated with immediate evacuation [23]. However, that analysis did not consider the psychological processes and various background factors.

Understanding the roles of psychological processes and personality factors in adaptive tsunami evacuation will contribute to the literature on risk perception, which has been dominated by research on technological or social risks. However, unique characteristics of disasters linked to natural hazards with respect to risk have been suggested. For example, the psychometric structure of the risk concept seems to be three-dimensional for such natural disasters [24], in contrast to the two dimension characterizing other types of risks [25]. Cultural effects seem to be particularly important in natural disasters [21,26], while their importance is controversial in other contexts [27]. Concerning social amplification or attenuation of risk perception [28,29], despite some studies on media coverage [30], the effects of social information [31,32] and the gap between experts and the lay population [33] in the context of natural disasters have not been integrated within a unified framework $[6,34,35]$.

In fact, the integration of various factors and processes relevant to risk perception and protective action across different types of natural or technological disasters is recognized as an essential research target for the achievement of disaster-related sustainable development goals, which are embodied in the Sendai Framework (2015-2030) [36]. Understanding the contributions of psychological processes and personality factors is key to this endeavor, given that they are an invariant component of human-environment interactions. Centering on an understanding of human nature, we may draw 
an integrated cross-contextual picture covering the diverse patterns of interactions among various components of the environment in various types of disasters in various sociocultural contexts.

In this study, we explored the psychological processes and personality factors that lead to appropriate tsunami evacuation. We also analyzed the effects of various background factors on evacuation behavior and relevant psychological processes. To this end, we analyzed the data from survivors of the 2011 Tohoku earthquake and tsunami disaster [23]. The environmental cues associated with that tsunami were probably very clear to the residents due to the severity of the earthquake, as well as to the effective tsunami early warning system and mitigation policies in place in Japan [8]. We first examined whether the perception of risk or threat of the tsunami, or the remembrance of a past experience of a tsunami or evacuation drill, explained immediate or spontaneous evacuation after controlling for other background factors. If some of these psychological factors had significant effects, we then examined whether they were associated with background factors. In both analyses, we also examined whether personality factors had additional explanatory power. Eight factors related to the Power to Live [23] and Big Five personality scales were included as personality traits.

In these analyses, we were also interested in three specific practical questions. First, we explored whether normalcy bias in the evacuation context is a class of general optimistic bias. Normalcy (or normality, normalization) bias is the tendency to underestimate the risk or threat of a warned hazard, which hampers appropriate evacuation [37-39]. It is theoretically tempting to identify this context-specific bias with a general optimistic bias (or positive illusion), which is considered a characteristic of mentally healthy normal humans and promotes daily productivity [40]. However, this entails a tradeoff between disaster preparedness and a mentally healthy, productive daily life. We tested whether this dilemma is true by examining whether appropriate risk perception was predicted by personality traits negatively associated with the advantage of general optimistic bias; that is, a high degree of neuroticism [41] and a low degree of emotion regulation [42]. Second, we examined the relationship between the decision to evacuate and past experience of a tsunami evacuation. We were particularly interested in the psychological effects of there being no damage after a disaster, which lessens the subsequent perception of risk in various types of disasters linked to natural hazards [43-46]. That is, an experience of an unnecessary evacuation from a tsunami may enhance normalcy bias for a similar subsequent warning (i.e., a "cry wolf" effect), which could call for reconsiderations of warnings made "to be on the safe side". To test this possibility, we examined whether appropriate risk perception was inhibited by experience of an unnecessary past evacuation. Finally, we examined the contributions of past evacuation drills and three knowledge factors relevant to educational measures for disaster mitigation. Participation in evacuation drills was associated with more effective evacuation [17] and fewer causalities [16] during the 2011 Tohoku earthquake and tsunami disaster. Oral transmission of information regarding a past disaster improved the likelihood of appropriate evacuation by residents $[3,47,48]$. Scientific knowledge taught in schools about the link between an earthquake and a tsunami has also been shown to facilitate evacuation after an earthquake [1]. Additionally, tsunami memorials (memorial stones, shrines, and temples) are expected to help build awareness and help maintain memory of past events, as well as to ensure readiness for possible future events [10].

\section{Materials and Methods}

\subsection{Survey}

The participants in the original survey were 1412 survivors of the 2011 Tohoku earthquake and tsunami disaster [10]. A questionnaire battery was sent to 3600 residents who were randomly sampled from the electoral registers (and thus were aged $\geq 20$ years) of tsunami-affected districts or temporary settlements in the four most populous coastal cities (Ishinomaki, Kesen-numa, Natori, and Sendai) in Miyagi Prefecture, where the damage caused by the earthquake and tsunami was most severe (3957, 1426,993 , and 937 dead or missing persons among the total populations of $160,826,73,489,73,134$, 
and 1,045,986, respectively [49]). In total, 1412 questionnaires (39\%) were anonymously completed and returned by mid-January 2014. Among the respondents, $68 \%$ evacuated to avoid the tsunami on 11 March 2011; 8\% lost family members; $38 \%$ lost friends; $48 \%$ lost their homes entirely; and $40 \%$ had partially-damaged homes. While we intended to include representative samples of tsunami survivors, the sociodemographic status of the selected cities, as well as various factors differing between responders and non-responders comprised potential sources of bias. The survey was approved by the Ethics Committee for Surveys and Experiments of the Graduate School of Arts and Letters, Tohoku University (2012-1019-190749) and conducted with support from Survey Research Center Co., Ltd. (Tokyo, Japan); see [10] for further details. The original questionnaire is available as Supplementary Information. The current analysis used data from 959 subjects who reported that they eventually evacuated to avoid the tsunami on 11 March 2011.

\subsection{Variables}

Self-evaluation data regarding whether the respondents evacuated immediately following the earthquake, and did so of their own volition rather than being prompted by someone else, were used as dependent variables for an appropriate tsunami evacuation. Four psychological processes, which were used both as independent and dependent variables, included two perception items (whether they perceived the risk and threat of the tsunami) and two remembrance items (whether they remembered a past tsunami experience and evacuation drill). In the original language (Japanese) "threat" has explicit connotations of fear, but "risk" does not. The background factors, which were used only as independent variables, included two demographic factors (sex and age), two environmental factors, five experiential factors, and three knowledge factors. The environmental factors concerned the perception of environmental cues associated with the tsunami, including earthquake severity (whether they observed phenomena that were informative regarding the severity of the earthquake, such as cracks, cave-ins, or liquefaction of roads soon after the earthquake) and warnings (whether they heard the official evacuation alert in any form, such as radio, TV, cell phone, or outdoor loudspeaker). The experiential factors included three types of experience pertaining to past tsunamis (whether they had observed a tsunami, experienced a flooded home, or were physically involved in a tsunami) and three related to evacuation experience (whether they had an effective, ineffective, or failed evacuation), as well as an item on evacuation drills (frequency of participation therein per year). Knowledge factors included familiarity with local tsunamis based on oral accounts (i.e., whether they had heard about past tsunami experiences from relatives often, occasionally, or never), the extent of their knowledge of the mechanism underlying the occurrence of a tsunami (detailed knowledge, some knowledge, little knowledge, or no knowledge), and "tsunami memorials" (whether they were aware of historical monuments related to previous earthquake disasters in that area). Table 1 lists the questions and basic statistics.

Table 1. Variables for evacuation, psychological processes, and background factors.

\begin{tabular}{|c|c|}
\hline \multicolumn{2}{|r|}{ Appropriate Tsunami Evacuation } \\
\hline 1. & Immediate evacuation: Did you evacuate immediately after the earthquake? (yes: 510 (54\%), no: 440 (46\%)) \\
\hline 2. & $\begin{array}{l}\text { Voluntary evacuation: Did you evacuate voluntarily soon after the earthquake before being encouraged by someone } \\
\text { else? (yes: } 467(50 \%) \text {, no: } 475(50 \%) \text { ) }\end{array}$ \\
\hline \multicolumn{2}{|r|}{ Psychological Processes } \\
\hline 1. & $\begin{array}{l}\text { Perception of risk: When you felt the quake, did you think there was a risk that a tsunami would follow? (yes: } 420 \\
(44 \%) \text {, no: } 529(56 \%))\end{array}$ \\
\hline 2. & $\begin{array}{l}\text { Perception of threat: Did you feel the threat of a tsunami coming soon after the quake? (yes: } 413 \text { (44\%), no: } 529 \\
(56 \%))\end{array}$ \\
\hline 3. & $\begin{array}{l}\text { Remembrance of tsunami experience: Did you remember a past tsunami soon after a quake (if you had no } \\
\text { experience of a tsunami, choose no)? (yes: } 168(18 \%) \text {, no: } 779(82 \%) \text { ) }\end{array}$ \\
\hline & $\begin{array}{l}\text { Remembrance of evacuation drills: Did you remember evacuation or disaster prevention drills soon after a quake } \\
\text { (if you had no experience of these drills, choose no)? (yes: } 223(24 \%) \text {, no: } 721(76 \%) \text { ) }\end{array}$ \\
\hline
\end{tabular}


Table 1. Cont.

\begin{tabular}{|c|c|}
\hline \multicolumn{2}{|r|}{ Background Factors } \\
\hline \multicolumn{2}{|r|}{ Demographic Factors } \\
\hline 1. & Sex (male: $376(40 \%)$, female: $575(60 \%))$ \\
\hline 2. & $\begin{array}{l}\text { Age (20s: } 50(5 \%), 30 \text { s: } 95(10 \%), 40 \text { s: } 153(16 \%), 50 \text { s: } 183(19 \%), 60 \text { s: } 270(28 \%), 70 \text { s: } 198(21 \%), 80 \text { years or } \\
\text { older: } 3(0 \%))\end{array}$ \\
\hline \multicolumn{2}{|r|}{ Environmental Factors } \\
\hline 3. & $\begin{array}{l}\text { Earthquake severity: Did you see any of the following phenomena on the roadway around you soon after the } \\
\text { earthquake: cracks, cave-ins, or liquefaction? (yes: } 495(53 \%) \text {, no: } 437(47 \%))\end{array}$ \\
\hline 4. & $\begin{array}{l}\text { Warning: Did you hear the call for an evacuation (evacuation recommendation) by any of the following methods? } \\
\text { Radio, TV, cell phone, outdoor loudspeaker, others (yes: } 707(77 \%) \text {, no: } 213(23 \%) \text { ) }\end{array}$ \\
\hline \multicolumn{2}{|r|}{ Experience Factors } \\
\hline & $\begin{array}{l}\text { Past tsunami: Have you had any of the following experiences with a tsunami in the past? Observed, home flooded, } \\
\text { been involved. (yes: } 231(25 \%) \text {, no: } 709(75 \%) \text { ) }\end{array}$ \\
\hline & 6-8. Have you had one of the following experiences with a tsunami evacuation in the past?* \\
\hline $6 .^{*}$ & Past effective evacuation - evacuated and escaped from a tsunami (selected: 62 (7\%), not selected: 850 (93\%)) \\
\hline 7.* & Past no-evacuation - not evacuated and tsunami came (selected: 109 (12\%), not selected: 803 (88\%)) \\
\hline $8 .^{*}$ & Past vain evacuation - evacuated but tsunami did not come (selected: $204(22 \%)$, not selected: 708 (78\%)) \\
\hline & $\begin{array}{l}\text { Past evacuation drills: How often have you participated in evacuation or disaster-prevention drills? (per year) } \\
\text { (three times or more: } 9(1 \%) \text {, twice: } 46(5 \%) \text {, once: } 266(28 \%) \text {, never: } 624(66 \%) \text { ) }\end{array}$ \\
\hline \multicolumn{2}{|r|}{ Knowledge Factors } \\
\hline & $\begin{array}{l}\text { Oral history: Have you heard of past tsunami experiences from relatives? (often: } 142 \text { (15\%), occasionally: } 511 \\
(54 \%) \text {, never: } 299(31 \%))\end{array}$ \\
\hline & $\begin{array}{l}\text { Scientific knowledge: Do you know the mechanism for the occurrence of a tsunami? (detailed knowledge: } 48 \\
(5 \%) \text {, some knowledge: } 414(44 \%) \text {, little knowledge: } 327(34 \%) \text {, no knowledge: } 160(17 \%))\end{array}$ \\
\hline & $\begin{array}{l}\text { Tsunami memorials: Are you aware of historical objects, such as monuments, that tell of past earthquake disasters } \\
\text { in the area where you live? (yes: } 182(19 \%) \text {, no: } 777(81 \%))\end{array}$ \\
\hline
\end{tabular}

Two personality trait inventories were included (Table 2). The Power to Live scale includes eight factors: leadership, problem solving, altruism, stubbornness, etiquette, emotion regulation, self-transcendence, and active well-being. The questionnaire was comprised of 34 items describing ways of thinking, daily attitude, or habit, and each factor was composed of three to five items. The internal consistency and concurrent validity of the questionnaire have been demonstrated [10]. The participants rated the applicability of each description using a six-point scale (0: not at all; 5 : very much). The Big Five personality scale includes extraversion, agreeableness, conscientiousness, neuroticism, and openness, which were measured using the Japanese version of the Ten-Item Personality Inventory [50,51], which includes one positive item and one reverse-scored item for each dimension. We adopted this very short version of the Big Five inventory to minimize respondents' fatigue or frustration, which may have decreased the rate and quality of the responses. The validity of this very short version of the Big Five inventory has been established in terms of convergent and discriminant validity, coverage of sub-dimensions, test-retest reliability, and patterns of external correlates [50,51]. The participants responded using a six-point scale (0: not at all; 5 : very much), and the scores of reverse items were reverse-coded. For each factor or dimension, the sum of the scores was converted to a percentile of the maximum total score for the basic statistics (Table 2) and normalized to a mean of 0 and a standard deviation of 1 when entered into the statistical model. 
Table 2. Variables for personality traits.

\begin{tabular}{|c|c|}
\hline \multicolumn{2}{|r|}{ Power to Live } \\
\hline 1. & Leadership: I gather together everyone involved to discuss how to resolve a problem. (52 \pm 19$)$ \\
\hline 2. & Problem Solving: When I am fretting about what I should do, I compare several alternative actions. (66 \pm 16$)$ \\
\hline 3. & Altruism: I like it when other people rely on me and are grateful to me. $(63 \pm 16)$ \\
\hline 4 . & Stubbornness: I am stubborn and always get my own way. $(59 \pm 17)$ \\
\hline 5. & $\begin{array}{l}\text { Etiquette: On a daily basis, I take the initiative when greeting family members and people living in the } \\
\text { neighborhood. }(83 \pm 15)\end{array}$ \\
\hline 6. & Emotion Regulation: I endeavor not to brood during difficult times. $(67 \pm 16)$ \\
\hline 7. & Self-transcendence: I am aware that I am alive and have a sense of responsibility in living. (72 \pm 16$)$ \\
\hline 8 . & $\begin{array}{l}\text { Active Well-being: In everyday life, I have habitual practices that are essential for relieving stress or giving me a } \\
\text { change of pace. }(58 \pm 21)\end{array}$ \\
\hline \multicolumn{2}{|r|}{ Big Five Dimensions } \\
\hline & Extraversion: I think I am enthusiastic and extraverted. $(51 \pm 20)$ \\
\hline 2. & Agreeableness: I think I am sympathetic and warm. $(70 \pm 17)$ \\
\hline & Conscientiousness: I think I am dependable and self-disciplined. $(57 \pm 20)$ \\
\hline & Neuroticism: I think I am anxious and easily upset. (50 \pm 19$)$ \\
\hline & Openness: I think I like new things and have unusual ideas. $(48 \pm 21)$ \\
\hline
\end{tabular}

\subsection{Analysis}

Logistic regression analyses were performed using IBM SPSS Statistics 25 (IBM Corp., Armonk, NY, USA). For exploratory purposes, we reported significant findings at $p<0.05$ corrected for multiple comparisons using the Bonferroni method based on the number of independent variables entered in each analysis. We also reported findings significant at an uncorrected $p<0.05$ level for a priori hypothesis testing.

\subsubsection{Factors Determining an Appropriate Tsunami Evacuation}

A hierarchical logistic regression analysis was performed separately including each of the two variables for appropriate tsunami evacuation as a dependent variable. For each analysis, 12 background-factor variables were entered as the first block to determine whether the effects of these variables would be replicated as demonstrated in previous studies. Then, we entered the four psychological-process variables as a second block, expecting their significant contributions and disappearance of the effects of the background factors if the former were indeed the principal mediators of appropriate evacuation.

Each personality trait variable was entered separately, rather than the 13 variables altogether, as the third block; that is, 13 separate analyses were performed on the third block only to avoid collinearity due to the relatively high correlations across personality trait scores. The condition index of the model including the first and second blocks was 15.82, while that of the model additionally including the 13 trait variables was 42.96 , which would have a serious collinearity problem [52].

\subsubsection{Factors Determining the Psychological Processes Related to Evacuation}

If some of these psychological factors had a significant effect, we performed a hierarchical logistic regression analysis including each of these variables. Twelve background factor variables were entered for each analysis. For the analysis on threat perception, the risk perception was entered as the second block, given that the former was likely to depend on the latter. Each personality trait was then entered separately as an additional block. 


\section{Results}

\subsection{Factors Determining Appropriate Tsunami Evacuation}

Tables 3 and 4 list the results of the hierarchical logistic regression analysis for an immediate tsunami evacuation. When the background factors were entered as the first block, oral history and scientific knowledge contributed significantly, while only the former survived the correction for multiple comparisons. When the psychological processes were entered as the second block, perception of risk and perception of threat revealed significant contributions, while the effect of oral history or scientific knowledge became non-significant (Table 3), implying the primary importance of these perceptual processes in immediate evacuation. Among the personality trait variables entered as the third block, extraversion and neuroticism revealed significant positive and negative contributions (i.e., Wald statistics of $\beta$ ), respectively, but neither survived the correction (Table 4).

Table 3. Contributions of background factors and psychological processes to an immediate tsunami evacuation.

\begin{tabular}{|c|c|c|c|c|c|c|c|c|}
\hline & \multicolumn{4}{|c|}{ Block 1} & \multicolumn{4}{|c|}{ + Block 2} \\
\hline & $\beta$ & Wald & & $\operatorname{Exp}(\beta)$ & $\beta$ & Wald & & $\operatorname{Exp}(\beta)$ \\
\hline \multicolumn{9}{|l|}{ Block 1 Background Factors } \\
\hline 1. Sex & -0.233 & 2.257 & & 0.792 & -0.211 & 1.666 & & 0.809 \\
\hline 2. Age & -0.021 & 0.155 & & 0.979 & -0.034 & 0.361 & & 0.967 \\
\hline 3. Earthquake severity & 0.186 & 1.629 & & 1.205 & 0.054 & 0.121 & & 1.055 \\
\hline 4. Warning & 0.184 & 1.025 & & 1.202 & -0.030 & 0.024 & & 0.970 \\
\hline 5. Past tsunami & -0.018 & 0.006 & & 0.982 & -0.062 & 0.063 & & 0.940 \\
\hline 6. Past effective evacuation & 0.296 & 0.706 & & 1.344 & 0.288 & 0.603 & & 1.334 \\
\hline 7. Past no-evacuation & 0.100 & 0.133 & & 1.105 & 0.146 & 0.253 & & 1.157 \\
\hline 8. Past vain evacuation & 0.127 & 0.442 & & 1.136 & -0.106 & 0.264 & & 0.900 \\
\hline 9. Past evacuation drills & 0.213 & 3.014 & & 1.238 & 0.112 & 0.609 & & 1.118 \\
\hline 10. Oral history & 0.374 & 9.175 & $* *$ & 1.453 & 0.246 & 3.529 & & 1.280 \\
\hline 11. Scientific knowledge & 0.245 & 5.901 & * & 1.278 & 0.151 & 1.990 & & 1.163 \\
\hline 12. Tsunami memorials & 0.370 & 3.263 & & 1.447 & 0.281 & 1.693 & & 1.324 \\
\hline \multicolumn{9}{|l|}{ Block 2 Psychological Processes } \\
\hline 1. Perception of risk & & & & & 0.834 & 18.214 & ** & 2.302 \\
\hline 2. Perception of threat & & & & & 0.752 & 14.501 & $* *$ & 2.122 \\
\hline $\begin{array}{l}\text { 3. Remembrance of a } \\
\text { tsunami experience }\end{array}$ & & & & & -0.309 & 1.463 & & 0.734 \\
\hline \multirow[t]{2}{*}{$\begin{array}{l}\text { Remembrance of } \\
\text { evacuation drills }\end{array}$} & & & & & 0.171 & 0.623 & & 1.186 \\
\hline & & & & $d f$ & & & & $d f$ \\
\hline Block $\chi^{2}$ & & 50.203 & * & 12 & & 75.014 & * & 4 \\
\hline Model $\chi^{2}$ & & 50.203 & * & 12 & & 125.217 & * & 16 \\
\hline Nagelkerke $R^{2}$ & & 0.079 & & & & 0.189 & & \\
\hline AIC & & 1107.476 & & & & 1040.462 & & \\
\hline
\end{tabular}

The results of the hierarchical logistic regression analysis are given as $\beta$, Wald statistic, and $\operatorname{Exp}(\beta)$ (odds) for each variable and block $\chi^{2}$, model $\chi^{2}$, Nagelkerke $R^{2}$ [53], and Akaike's information criterion (AIC) separately for each block. *: $p<0.05$, uncorrected; **: $p<0.05$ after correction for the multiple comparisons of the 16 variables (only for $\beta$ ). 
Table 4. Contributions of personality traits to an immediate tsunami evacuation.

\begin{tabular}{|c|c|c|c|c|c|c|c|c|}
\hline & \multicolumn{4}{|c|}{ + Block 3} & \multicolumn{4}{|c|}{ Model } \\
\hline & $\beta$ & Wald & & $\operatorname{Exp}(\beta)$ & $\chi^{2}(17)$ & & $\begin{array}{l}\text { Nagelkerke } \\
\qquad R^{2}\end{array}$ & AIC \\
\hline \multicolumn{9}{|l|}{ Power to Live } \\
\hline 1. Leadership & 0.152 & 3.328 & & 1.164 & 117.857 & * & 0.195 & 950.488 \\
\hline 2. Problem solving & 0.123 & 2.149 & & 1.131 & 116.660 & * & 0.193 & 951.685 \\
\hline 3. Altruism & 0.068 & 0.673 & & 1.070 & 115.179 & * & 0.191 & 953.167 \\
\hline 4. Stubbornness & 0.072 & 0.774 & & 1.075 & 115.280 & * & 0.191 & 953.065 \\
\hline 5. Etiquette & 0.028 & 0.100 & & 1.028 & 114.605 & * & 0.190 & 953.740 \\
\hline 6. Emotion regulation & 0.150 & 3.264 & & 1.162 & 117.792 & * & 0.195 & 950.554 \\
\hline 7. Self-transcendence & 0.001 & 0.000 & & 1.001 & 114.506 & * & 0.190 & 953.840 \\
\hline 8. Active well-being & 0.106 & 1.583 & & 1.112 & 116.092 & * & 0.192 & 952.254 \\
\hline \multicolumn{9}{|l|}{ Big Five Dimensions } \\
\hline 1. Extraversion & 0.168 & 4.362 & * & 1.183 & 122.557 & * & 0.199 & 961.936 \\
\hline 2. Agreeableness & 0.134 & 2.709 & & 1.144 & 120.876 & * & 0.197 & 963.617 \\
\hline 3. Conscientiousness & 0.038 & 0.205 & & 1.039 & 118.363 & * & 0.193 & 966.131 \\
\hline 4. Neuroticism & -0.162 & 4.006 & * & 0.850 & 122.189 & * & 0.199 & 962.305 \\
\hline 5. Openness & 0.077 & 0.894 & & 1.080 & 119.052 & * & 0.194 & 965.441 \\
\hline
\end{tabular}

The results of the hierarchical logistic regression analysis for each personality trait variable are entered as the third block. Each variable was entered separately to avoid a collinearity problem. Other details are the same as for Table 3.

Tables 5 and 6 list the results of the hierarchical logistic regression analysis for a voluntary tsunami evacuation. When the background factors were entered as the first block, sex (being female), earthquake severity, warning, and experience of past evacuation drills had significant contributions, but none of them survived the correction. When the psychological processes were entered as the second block, perception of risk and perception of threat revealed significant contributions, but the contributions of background factors became non-significant except that of sex (Table 5), suggesting the primary importance of these perceptual processes in voluntary evacuation. Among the personality trait variables entered as the third block, leadership, active well-being, and extraversion had significant positive contributions at the corrected level. Problem solving, altruism, stubbornness, emotion regulation, and openness had positive contributions, and neuroticism had a negative contribution at an uncorrected level (Table 6).

Table 5. Contributions of background factors and psychological processes to voluntary tsunami evacuation.

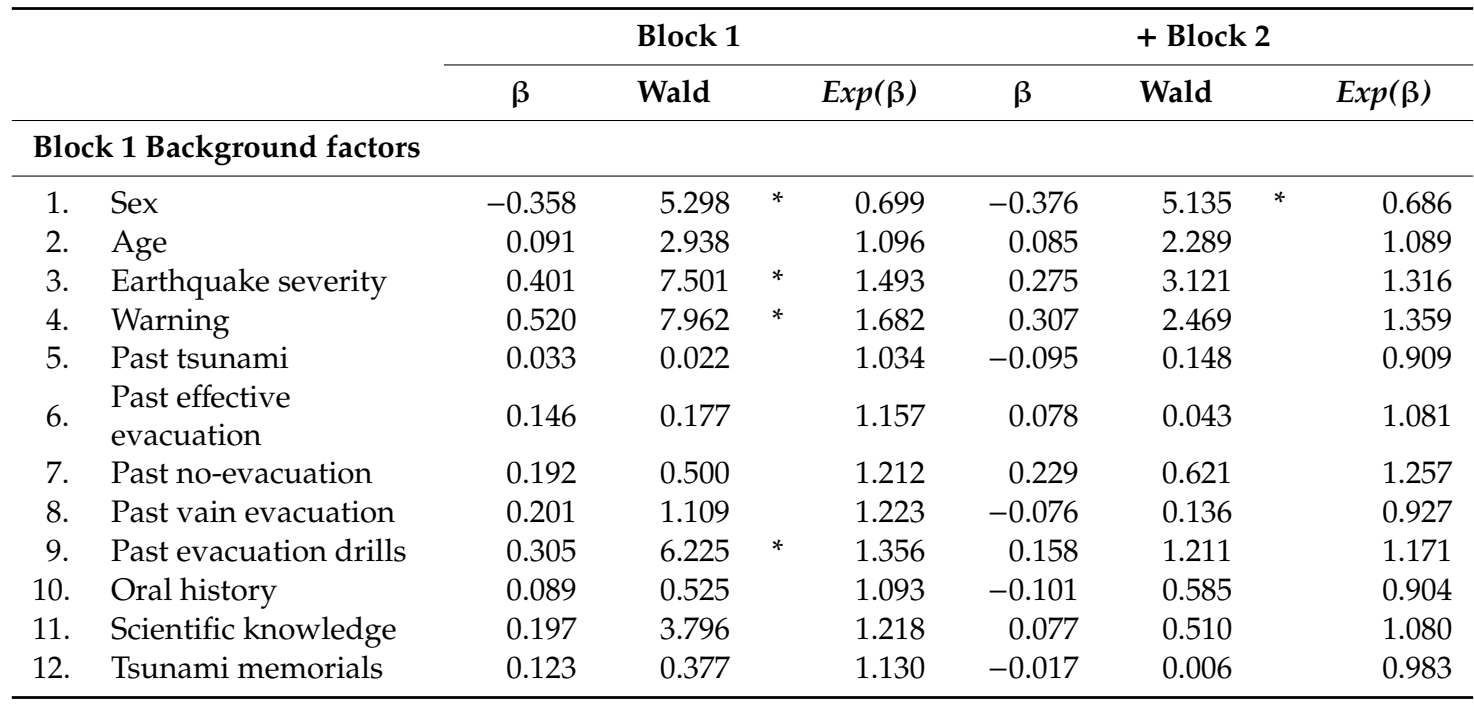


Table 5. Cont.

\begin{tabular}{|c|c|c|c|c|c|c|}
\hline & \multicolumn{2}{|l|}{ Block 1} & \multicolumn{4}{|c|}{ + Block 2} \\
\hline & Wald & $\operatorname{Exp}(\beta)$ & $\beta$ & Wald & & $\operatorname{Exp}(\beta)$ \\
\hline \multicolumn{7}{|c|}{ Block 2 Psychological Processes } \\
\hline 1. Perception of risk & & & 0.925 & 22.492 & ** & 2.522 \\
\hline 2. Perception of threat & & & 0.737 & 14.105 & ** & 2.089 \\
\hline $\begin{array}{l}\text { Remembrance of } \\
\text { tsunami experience }\end{array}$ & & & -0.016 & 0.004 & & 0.984 \\
\hline $\begin{array}{l}\text { 4emembrance of } \\
\text { evacuation drills }\end{array}$ & & & 0.344 & 2.506 & & 1.411 \\
\hline & & $d f$ & & & & $d f$ \\
\hline Block $\chi^{2}$ & 49.197 & 12 & & 88.369 & * & 4 \\
\hline Model $\chi^{2}$ & 49.197 & 12 & & 137.566 & * & 16 \\
\hline Nagelkerke $R^{2}$ & 0.078 & & & 0.207 & & \\
\hline AIC & 1108.020 & & & 1027.651 & & \\
\hline
\end{tabular}

Details are the same as for Table 3.

Table 6. Contributions of personality traits to voluntary tsunami evacuation.

\begin{tabular}{|c|c|c|c|c|c|c|c|c|}
\hline & \multicolumn{4}{|c|}{ + Block 3} & \multicolumn{4}{|c|}{ Model } \\
\hline & $\beta$ & Wald & & $\operatorname{Exp}(\beta)$ & $x^{2}(17)$ & & $\begin{array}{l}\text { Nagelkerke } \\
\qquad R^{2}\end{array}$ & AIC \\
\hline \multicolumn{9}{|l|}{ Power to Live } \\
\hline Leadership & 0.327 & 14.835 & $* *$ & 1.387 & 133.398 & $*$ & 0.219 & 935.283 \\
\hline 2. Problem solving & 0.203 & 5.753 & * & 1.225 & 123.891 & * & 0.204 & 944.789 \\
\hline Altruism & 0.216 & 6.719 & * & 1.241 & 124.862 & * & 0.206 & 943.818 \\
\hline Stubbornness & 0.224 & 7.215 & * & 1.251 & 125.392 & * & 0.207 & 943.288 \\
\hline Etiquette & 0.027 & 0.092 & & 1.027 & 118.156 & * & 0.196 & 950.524 \\
\hline 6. Emotion regulation & 0.175 & 4.385 & * & 1.191 & 122.497 & * & 0.202 & 946.184 \\
\hline 7. Self-transcendence & 0.123 & 2.118 & & 1.131 & 120.189 & * & 0.199 & 948.492 \\
\hline 8. Active well-being & 0.281 & 10.645 & $* *$ & 1.325 & 128.934 & * & 0.212 & 939.746 \\
\hline \multicolumn{9}{|l|}{ Big Five Dimensions } \\
\hline 1. Extraversion & 0.332 & 16.480 & ** & 1.394 & 135.090 & * & 0.218 & 950.175 \\
\hline 2. Agreeableness & 0.090 & 1.244 & & 1.095 & 119.313 & * & 0.194 & 965.952 \\
\hline 3. Conscientiousness & 0.046 & 0.310 & & 1.048 & 118.376 & * & 0.193 & 966.889 \\
\hline 4. Neuroticism & -0.228 & 7.863 & * & 0.796 & 126.048 & * & 0.205 & 959.217 \\
\hline 5. Openness & 0.202 & 6.124 & * & 1.224 & 124.262 & * & 0.202 & 961.003 \\
\hline
\end{tabular}

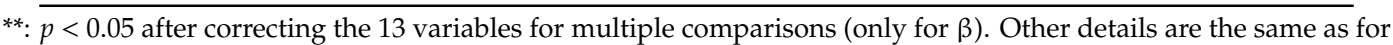
Table 4 .

\subsection{Factors Determining the Psychological Processes Related to Evacuation}

Because perception of risk and threat significantly contributed to both immediate and voluntary evacuation, a hierarchical logistic regression analysis was performed for each of these processes.

Tables 7 and 8 list the results of the hierarchical logistic regression analysis on the risk perception of a tsunami. When the background factor was entered as the first block, earthquake severity, warning, past vain evacuation, oral history, and scientific knowledge revealed significant contributions, all of which survived the correction (Table 7). The personality trait variables were then entered as the second block, but none of them had a significant contribution, even at an uncorrected level (Table 8). 
Table 7. Contributions of background factors to risk perception of a tsunami.

\begin{tabular}{|c|c|c|c|c|c|}
\hline & & $\beta$ & Wald & & $\operatorname{Exp}(\beta)$ \\
\hline \multicolumn{6}{|c|}{ Block 1 Background factors } \\
\hline 1. & Sex & -0.001 & 0.000 & & 0.999 \\
\hline 2. & Age & 0.041 & 0.523 & & 1.042 \\
\hline 3. & Earthquake severity & 0.452 & 8.575 & $* *$ & 1.571 \\
\hline 4. & Warning & 0.626 & 9.909 & $* *$ & 1.871 \\
\hline 5. & Past tsunami & 0.433 & 3.427 & & 1.541 \\
\hline 6. & $\begin{array}{l}\text { Past effective } \\
\text { evacuation }\end{array}$ & 0.111 & 0.096 & & 1.117 \\
\hline 7. & Past no-evacuation & 0.075 & 0.070 & & 1.077 \\
\hline & Past vain evacuation & 0.709 & 13.195 & $* *$ & 2.032 \\
\hline & Past evacuation drills & 0.135 & 1.164 & & 1.144 \\
\hline 10. & Oral history & 0.565 & 19.076 & $* *$ & 1.759 \\
\hline & Scientific knowledge & 0.366 & 11.550 & $* *$ & 1.441 \\
\hline & Tsunami memorials & 0.216 & 1.108 & & 1.241 \\
\hline \multicolumn{3}{|c|}{ Model $\chi^{2}(12)$} & 137.493 & * & \\
\hline \multicolumn{3}{|c|}{ Nagelkerke $R^{2}$} & 0.203 & & \\
\hline \multicolumn{3}{|c|}{ AIC } & 1032.399 & & \\
\hline
\end{tabular}

Table 8. Contributions of personality traits to risk perception of a tsunami.

\begin{tabular}{|c|c|c|c|c|c|c|c|c|}
\hline & & \multicolumn{3}{|c|}{+ Block 2} & \multicolumn{3}{|c|}{ Model } & \multirow[b]{2}{*}{ AIC } \\
\hline & & $\beta$ & Wald & $\operatorname{Exp}(\beta)$ & $\chi^{2}(13)$ & & $\begin{array}{l}\text { Nagelkerke } \\
\qquad R^{2}\end{array}$ & \\
\hline \multicolumn{9}{|c|}{ Power to Live } \\
\hline 1. & Leadership & 0.076 & 0.832 & 1.078 & 118.774 & * & 0.195 & 941.403 \\
\hline 2. & $\begin{array}{l}\text { Problem } \\
\text { solving }\end{array}$ & 0.053 & 0.402 & 1.054 & 118.342 & $*$ & 0.194 & 941.835 \\
\hline 3. & Altruism & -0.011 & 0.018 & 0.989 & 117.957 & * & 0.194 & 942.219 \\
\hline 4. & Stubbornness & 0.025 & 0.092 & 1.025 & 118.031 & * & 0.194 & 942.145 \\
\hline 5. & Etiquette & 0.057 & 0.425 & 1.059 & 118.365 & * & 0.194 & 941.812 \\
\hline 6. & $\begin{array}{l}\text { Emotion } \\
\text { regulation }\end{array}$ & 0.062 & 0.565 & 1.064 & 118.505 & * & 0.194 & 941.672 \\
\hline 7. & Self-transcendence & 0.064 & 0.580 & 1.066 & 118.520 & * & 0.194 & 941.656 \\
\hline 8. & $\begin{array}{l}\text { Active } \\
\text { well-being }\end{array}$ & 0.031 & 0.138 & 1.032 & 118.077 & * & 0.194 & 942.099 \\
\hline \multicolumn{9}{|c|}{ Big Five Dimensions } \\
\hline 1. & Extraversion & 0.062 & 0.586 & 1.064 & 124.392 & * & 0.200 & 956.932 \\
\hline 2. & Agreeableness & 0.089 & 1.206 & 1.093 & 125.014 & * & 0.201 & 956.309 \\
\hline 3. & Conscientiousness & 0.025 & 0.086 & 1.025 & 123.891 & * & 0.199 & 957.432 \\
\hline 4. & Neuroticism & -0.087 & 1.150 & 0.917 & 124.958 & * & 0.201 & 956.365 \\
\hline 5. & Openness & -0.010 & 0.014 & 0.990 & 123.819 & * & 0.199 & 957.504 \\
\hline
\end{tabular}

Details are the same as for Table 6.

Tables 9 and 10 list the results of the hierarchical logistic regression analysis regarding threat perception of a tsunami. When the background factor was entered as the first block, warning, past vain evacuation, oral history, and scientific knowledge revealed significant contributions at the corrected level. The contributions of earthquake severity, past evacuation drills, and tsunami memorials were also significant at the uncorrected level. When the risk perception was entered as the second block, this revealed a highly significant contribution, and the contributions of most of the background factors became non-significant. However, the contributions of warning and past evacuation drills (at 
an uncorrected level) remained significant, implying their specific contribution to threat perception (Table 9). The personality trait variables were entered as the third block, but none of them had a significant contribution, even at the uncorrected level (Table 10).

Table 9. Contributions of background factors and risk perception to threat perception of a tsunami.

\begin{tabular}{|c|c|c|c|c|c|c|c|c|}
\hline & \multicolumn{4}{|c|}{ Block 1} & \multicolumn{4}{|c|}{ + Block 2} \\
\hline & $\beta$ & Wald & & $\operatorname{Exp}(\beta)$ & $\beta$ & Wald & & $\operatorname{Exp}(\beta)$ \\
\hline \multicolumn{9}{|l|}{ Block 1 Background Factors } \\
\hline 1. Sex & -0.213 & 1.717 & & 0.808 & -0.335 & 2.799 & & 0.715 \\
\hline 2. Age & 0.031 & 0.307 & & 1.032 & 0.009 & 0.015 & & 1.009 \\
\hline 3. Earthquake severity & 0.415 & 7.253 & * & 1.514 & 0.239 & 1.597 & & 1.271 \\
\hline 4. Warning & 0.785 & 14.967 & ** & 2.193 & 0.649 & 6.932 & * & 1.914 \\
\hline 5. Past tsunami & 0.247 & 1.119 & & 1.280 & -0.015 & 0.003 & & 0.986 \\
\hline 6. Past effective evacuation & 0.264 & 0.550 & & 1.302 & 0.328 & 0.531 & & 1.388 \\
\hline 7. Past no-evacuation & -0.127 & 0.199 & & 0.881 & -0.263 & 0.579 & & 0.768 \\
\hline 8. Past vain evacuation & 0.623 & 10.138 & ** & 1.865 & 0.288 & 1.445 & & 1.334 \\
\hline 9. Past evacuation drills & 0.299 & 5.672 & * & 1.348 & 0.340 & 4.883 & * & 1.405 \\
\hline 10. Oral history & 0.431 & 11.212 & ** & 1.538 & 0.149 & 0.893 & & 1.161 \\
\hline 11. Scientific knowledge & 0.344 & 10.308 & $* *$ & 1.411 & 0.216 & 2.785 & & 1.241 \\
\hline 12. Tsunami memorials & 0.417 & 4.162 & * & 1.517 & 0.458 & 3.293 & & 1.581 \\
\hline \multicolumn{9}{|l|}{ Block 2 Psychological Processes } \\
\hline 1. Perception of risk & & & & & 2.850 & 217.224 & $* *$ & 17.282 \\
\hline & & & & $d f$ & & & & $d f$ \\
\hline Block $\chi^{2}$ & & 125.022 & * & 12 & & 269.694 & * & 1 \\
\hline Model $\chi^{2}$ & & 125.022 & * & 12 & & 394.716 & * & 13 \\
\hline Nagelkerke $R^{2}$ & & 0.188 & & & & 0.509 & & \\
\hline AIC & & 1031.296 & & & & 763.602 & & \\
\hline
\end{tabular}

Details are the same as for Table 3 .

Table 10. Contributions of personality traits to threat perception of a tsunami.

\begin{tabular}{|c|c|c|c|c|c|c|c|}
\hline & \multicolumn{3}{|c|}{ + Block 3} & \multicolumn{4}{|c|}{ Model } \\
\hline & $\beta$ & Wald & $\operatorname{Exp}(\beta)$ & $\chi^{2}(14)$ & & $\begin{array}{l}\text { Nagelkerke } \\
\qquad R^{2}\end{array}$ & AIC \\
\hline \multicolumn{8}{|l|}{ Power to Live } \\
\hline 1. Leadership & -0.033 & 0.110 & 0.967 & 355.231 & * & 0.506 & 697.870 \\
\hline 2. Problem solving & -0.046 & 0.204 & 0.955 & 355.325 & * & 0.506 & 697.775 \\
\hline 3. Altruism & -0.089 & 0.779 & 0.914 & 355.903 & * & 0.507 & 697.198 \\
\hline 4. Stubbornness & 0.031 & 0.092 & 1.032 & 355.213 & * & 0.506 & 697.888 \\
\hline 5. Etiquette & -0.062 & 0.309 & 0.940 & 355.430 & * & 0.506 & 697.671 \\
\hline 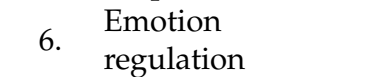 & -0.012 & 0.014 & 0.988 & 355.134 & * & 0.506 & 697.966 \\
\hline 7. Self-transcendence & 0.030 & 0.084 & 1.031 & 355.204 & * & 0.506 & 697.896 \\
\hline 8. Active well-being & 0.056 & 0.281 & 1.058 & 355.402 & * & 0.506 & 697.698 \\
\hline \multicolumn{8}{|l|}{ Big Five Dimensions } \\
\hline 1. Extraversion & -0.024 & 0.057 & 0.976 & 360.397 & * & 0.504 & 714.353 \\
\hline 2. Agreeableness & -0.160 & 2.602 & 0.852 & 362.965 & * & 0.507 & 711.785 \\
\hline 3. Conscientiousness & 0.119 & 1.316 & 1.126 & 361.661 & * & 0.505 & 713.089 \\
\hline 4. Neuroticism & 0.042 & 0.180 & 1.043 & 360.520 & * & 0.504 & 714.230 \\
\hline 5. Openness & -0.040 & 0.160 & 0.961 & 360.500 & * & 0.504 & 714.250 \\
\hline
\end{tabular}




\section{Discussion}

This study is the first to demonstrate the pivotal importance of the risk or threat perception of a hazard during appropriate evacuation from a tsunami, which has previously been demonstrated for other types of disasters [11,12]. Although several background factors contributed to immediate or voluntary evacuation, when these psychological processes were entered into the model, they mostly replaced the contributions of these background factors. The background factors contributed significantly to the psychological processes. Another striking finding was the contributions of some personality traits: leadership and active well-being in the Power to Live scale and extraversion in the Big Five dimensions added explanatory power to voluntary evacuation. Of note, these contributions directly affected voluntary evacuation; none of these traits contributed to risk or threat perception. The independent contributions of these psychological processes and personality traits were similar for immediate and voluntary evacuation, while their contributions were more robust for voluntary evacuation. Figure 1 presents a schematic summary of the dual contribution model formulated.

\section{Background factors Environmental \\ - Earthquake severity \\ - Warning \\ Knowledge \\ - Oral history \\ - Scientific knowledge}

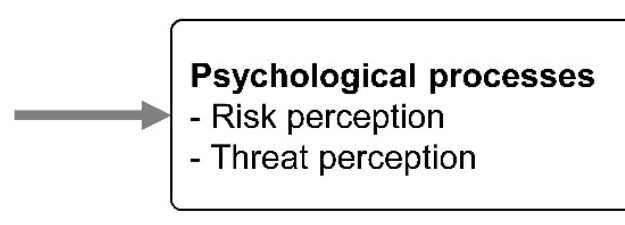

Psychological processes

- Threat perception

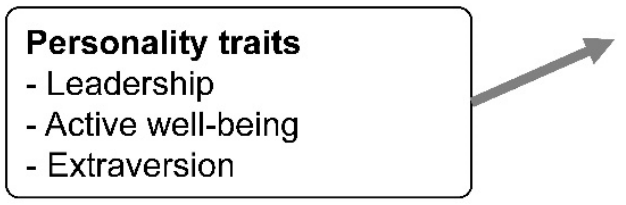

Appropriate evacuation

- Immediate evacuation

- Voluntary evacuation

Figure 1. Schematic summary of the major findings: dual contribution model.

\subsection{Perception of Risk and Threat}

Our results illustrate the importance of risk or threat perception, showing that it mediates the facilitating effect of several environmental or knowledge factors on tsunami evacuation. The demonstrated contributions of the knowledge factors (i.e., existence of oral history and scientific knowledge) to immediate evacuation and those of the environmental (i.e., perceived earthquake severity and warning) and experience factors (i.e., past evacuation drills) to voluntary evacuation are consistent with the findings of previous studies $[1,3,4,16,47,48]$. However, these contributions disappeared when the psychological factors were entered into the hierarchical regression model, and the background factors were demonstrated to be strong predictors of perceived risk or threat. The only exception was the effect of sex; females were more likely than males to evacuate voluntarily, as has been reported for other disasters [54], and this tendency remained significant (although at an uncorrected level) after entering the psychological factors in the regression model.

Threat perception contributed to appropriate evacuation independent of risk perception and was specifically enhanced by warnings and past evacuation drills (while at an uncorrected significance level). The independent contribution of threat perception identified herein is congruent with research on other types of disasters [11-15], while the substantial contribution of risk perception appears unique to tsunamis. The specific contributions of warnings and past evacuation drills to threat perception seem consistent with the notion that personalization of risk is enhanced by information that is specific, consistent, frequently repeated, and from official sources [44]; these characteristics appear relevant to the information delivered during official warnings and evacuation drills. While the contributions of these factors to threat perception and appropriate evacuation are plausible and practically important, they remain matters for future validation. First, it is unclear to what degree our responders understood the risk and threat we assumed; in fact, 81 respondents (9\%) replied that they did not perceive "risk", 
but perceived "threat," which is a pattern to which existing data on the roles of risk and threat perceptions do not point. Second, the significance of the contributions of warnings and past evacuation drills remained at an uncorrected level. Finally, an alternative explanation is also likely: seeking warning information, participating in evacuation drills, and perceiving a tsunami threat may all be promoted by the same personality factor (while we did not identify such a personality trait in the current results).

\subsection{Personality Traits}

The finding of direct contributions of personality traits to voluntary evacuation is congruent with the results of previous research on hurricane preparedness [20]. This implies that risk or threat perception is important, but not a prerequisite for an appropriate evacuation decision; this is supported by the fact that among 465 voluntarily-evacuated respondents, $179(39 \%)$ reported not perceiving "risk."

The contributions of two Power to Live factors, leadership and active well-being, to voluntary evacuation seem congruent with the suggested association between an internal locus of control and appropriate evacuation behavior in the context of a tornado or hurricane $[20,21]$. People who have an internal locus of control are considered more likely to attempt to improve their life conditions by controlling their environment during important life situations [19]. Previous research has demonstrated that an internal locus of control is associated with a lower casualty rate [21] and higher levels of preparedness [20]. Previous studies have also shown that an internal locus of control is associated with leadership $[55,56]$ and health-oriented behaviors $[57,58]$, pointing to its relevance to leadership and active well-being, respectively.

The commonality and difference between the internal locus of control and two Power to Live factors may be formulated within the framework of social learning theory [59]. Social learning theory assumes that behavioral decisions in a specific situation depend on the expectancy that the behavior will result in a particular outcome, as well as on the value of that outcome. Expectancy is determined by generalizing the experiences of the outcome in the same, as well as similar situations. Importantly, here, the situation can be broadly or narrowly formulated. The locus of control is conceptualized as very general behavior-outcome expectancy placed at the broadest end of the continuum of situation formulation. On the other hand, the leadership and active well-being factors may be conceptualized as general behavior-outcome expectancies under relatively narrow situation formulations. Speculatively, these expectancies are relevant to the expected outcomes of the behavior (e.g., evacuation) that merit community and one's own well-being, respectively.

However, the observed contribution of extraversion seems to lead to an independent story. The association between extraversion and voluntary evacuation in the current study appears consistent with the previously demonstrated association of extraversion with rational action [60] and problem-focused coping [61]. However, extraversion has been shown to be independent of the locus of control $[62,63]$. Further analysis of the contribution of this factor at the level of cognitive processes is not feasible because the cognitive mechanisms underlying the Big Five dimensions are unknown despite their popularity; surveys using twins have implied that each dimension is composed of multiple genetic and environmental factors shared among dimensions [64].

Before unequivocally accepting the contributions of these personality factors, the causal relationship between them and appropriate evacuation behavior should be discussed. The personality traits that we measured, particularly the eight factors captured by the Power to Live scale, are potentially affected by a disaster experience. Our attempt to identify the most evacuation-relevant personality factor was partially motivated by the possibility of devising an educational intervention pertaining to that factor, which assumes that it is amenable to change. There is also evidence that various personality factors are affected by traumatic experience (i.e., post-traumatic growth [65]). Accordingly, the following question is relevant: Did the personality factors affect the evacuation decision or did the specific decision affect personality? We consider the likelihood of the latter scenario to be very low. First, all of the responders whose data were analyzed eventually evacuated. Second, throughout 
the three-year post-evacuation period, the responders made hundreds of decisions critical to survival; it is unlikely that, among them, the single evacuation-specific decision had a substantial effect on their personality traits three years later. Finally, the effect of a similar personality trait on evacuation decision has been previously reported in the context of other types of disasters $[62,63]$. Accordingly, we consider our conclusion reasonable.

We previously reported the significant association of leadership, problem solving, and emotion regulation with immediate evacuation at a liberal threshold in an analysis validating the newly-created inventory of the Power to Live [23]. In the current analysis, including various background and psychological factors in the statistical model, these associations were subthreshold for immediate evacuation. However, they were significant for voluntary evacuation at an uncorrected level.

It is important to note that we used the very short version of the Big Five inventory. Although its content validity has been established [50,51], the results might have differed if the full-length version had been used.

\subsection{Practical Implications}

Our dual contribution model (Figure 1) legitimates the formulation of two independent targets in measures to promote an appropriate tsunami evacuation: facilitation of risk or threat perception and empowerment of the relevant personality factors. These two targets may be pursued in different contexts. Risk or threat perception is related to relevant environmental or knowledge factors in a relatively specific context of reducing tsunami disaster risk, whereas empowerment may be addressed in a rather broader context of disaster or general education and sociocultural activities, given the relevance of personality factors to our daily life. The model may also provide a framework to integrate various factors and processes relevant to risk perception and preventative actions in various types of disasters. This framework could then be incorporated within the social amplification/attenuation model to achieve the outcome and goals laid out in a recent disaster risk reduction model [36].

Facilitation of the perception of tsunami risk and threat may basically be pursued by developing existing approaches. Facilitation involves two phases: action in the face of an imminent tsunami cued by an earthquake and daily tsunami disaster mitigation education. For the former, our results support the importance of developing better warning systems in terms of availability for residents and the content of information. It may be more efficient to enhance perception not only of the tsunami risk, but also of the severity of an earthquake that has occurred. Methods to enhance the affective response to, or personalization [44] of, the tsunami risk are also worth considering. Our results largely support the importance of daily disaster mitigation education, particularly orally-conveyed local history and scientific knowledge of tsunamis. It is important to encourage scientific education about tsunami mechanisms and disaster mitigation. Oral history also has impressive effects, although it can be technically difficult within an educational context; construction of a tsunami memorial for this purpose seemed to have a marginal effect. The limited contribution of past evacuation drills was alarming, while its potential unique facilitatory effect on threat perception is noteworthy.

The idea of empowering personality traits to facilitate tsunami evacuation may be new, and discussions should begin by questioning whether this is socially acceptable and technically feasible. With regard to social acceptability, it seems reasonable to take a cautious stance when proposing an educational intervention to enhance extraversion among people in an entire society. This is because such broadly-formulated basic dimensions are considered largely innate and value-free (i.e., neither being extroverted nor introverted means being superior as a person). The leadership and active well-being factors on the Power to Live scale appear to be readily accepted as the target of educational intervention. While they are conceptualized as personality, each factor was narrowly formulated and expected to be malleable and value-laden (i.e., survival oriented) [23]. With regard to technical feasibility, this issue remains for future studies. However, it appears promising that the framework of the social learning theory [59] led to the development of an educational intervention technique for leadership and active well-being. Theoretically, repeated experience of a favorable outcome contingent on one's 
own behavior results in the acquisition of generalized behavior-outcome expectancies. Scholars should explore the types of behaviors, outcomes, and situations related to each factor; ideally, these can be implemented in education of daily life contexts to enhance that factor efficiently.

The dual contribution model provides a novel perspective on the issue of normalcy bias. A serious conceptual and practical concern was whether this bias is the opposite of optimism, which is assumed to support mentally healthy, productive daily life. Our results do not support this concern: neither risk nor threat perception (i.e., low normalcy bias) was predicted by high neuroticism or low emotion regulation, which had been implicated in those with low levels of optimism. Furthermore, low neuroticism and high emotion regulation did predict the likeliness of voluntary evacuation, which is opposite the prediction that optimism would hamper an appropriate evacuation. The implication of these results can be formulated into the framework of the dual contribution model as follows. On the one hand, in facilitating the risk or threat perception of a tsunami, we do not need to hesitate to demonize normalcy bias based on concerns about sacrificing the benefits of general optimism. On the other hand, for direct facilitation of tsunami evacuation regardless of risk perception, general optimism and related personality traits may be the target of empowerment (rather than suppression).

Our results do not support the "cry wolf" effect of experiencing an unnecessary evacuation before a tsunami, contrary to the findings of previous studies on other types of disasters [43-46]. Risk perception was positively, rather than negatively, associated with such an experience. Of course, it is unlikely that such an experience would enhance risk perception. It is likely that people who previously evacuated in vain would still tend to evacuate on the next occasion. The difference between the current and previous findings implies that the 'cry wolf' effect is dependent on the context or type of risk perception. Regarding tsunamis, we apparently do not need to be too cautious about avoiding unnecessary evacuations by issuing warnings that are on the safe side, although we do not know whether individuals would evacuate a third time.

\subsection{Limitations and Future Perspectives}

The survey was conducted nearly three years after the earthquake and tsunami. Any drawbacks common to such retrospective surveys, including the effect of limited memory accuracy and biases, also apply to this study. For example, it may have been difficult for the respondents to recall accurately what they were thinking soon after the earthquake, including whether they remembered a past tsunami experience or evacuation drills at that time. This limitation may explain the lack of association between these variables and appropriate evacuation in the current analysis. We also concede that some key terms in the survey questionnaire were not defined clearly enough, in part due to space and time limitations. In addition to the distinction between the "risk" and "threat" psychological processes, as already discussed, "immediate" evacuation was also somewhat ambiguous. Such ambiguity might have resulted in variation in the interpretation of these terms among responders, which in turn might have decreased the sensitivity of the analysis. This limitation should be considered when interpreting the negative findings. Several negative findings may also be attributable to suboptimal modeling. According to our interest in experiential and knowledge-related factors, and given concerns regarding multicollinearity, we decreased the number of variables in the analyses. For example, the effect of age was considered only in a linear manner, and the two environmental effects were entered only as binary variables. While more sophisticated modeling could have been performed, this would be more promising accompanied by further refinement of the survey itself (e.g., additional choice options for earthquake severity- or and warning-related items) in the future.

It is important to discuss the potential sample selection bias in this study: because the respondents were survivors, people who did not evacuate and died were "missing" from the sample. This bias may have had an impact on the results because it is tightly connected with the dependent variable (i.e., appropriate evacuation), although the magnitude of the effect was likely modest considering the casualty rate. This bias is likely to have caused false-negative rather than false-positive results. The factors facilitating evacuation would have been less relevant in the missing respondents, and the 
sampling bias could have caused a spurious increase in the scores on these factors of the respondents who did not evacuate (or perceive risk) appropriately. Therefore, we must carefully interpret the negative findings taking this selection bias into account. Nevertheless, we consider the positive findings robust because the effects were significant even under such a bias. Although there are other sources of sampling bias, concerning for example those who survived, but migrated after the disaster or did not respond to the survey, they are not directly associated with evacuation behavior, and their effects on the results are difficult to quantify. We are unaware of any reason to suspect that individuals who had high scores for the pro-evacuation factors (i.e., environmental, knowledge, and personality factors) and made an inappropriate evacuation or psychological response selectively migrated or did not respond. Potential bias related to region-specific population dynamics and non-respondents is a common challenge in various types of disaster research and should be addressed further in future investigations

In the current analysis, we did not take into consideration the contributions of social structure or community resources to evacuation behavior, which have been demonstrated in the context of a previous tsunami [48] and other disasters [11]. This limitation may be reflected in the less significant contributions of background and personality factors to immediate than to voluntary evacuation; that is, immediateness seemed to be more affected by community resources. In support of this, the effect of oral history, which is typically shared within the community, had an opposite pattern. The logistic regression analysis at the step before the psychological processes were entered revealed a strong contribution of oral history to immediate, but not voluntary, evacuation. In a community where such oral history is shared, people may be immediately encouraged to evacuate by other family or community members before they voluntarily decide to do so.

Our findings do not support a contribution of past tsunami experience to appropriate evacuation, as demonstrated previously [7]. Although we accept that this may be due to limitations in our survey and analysis, we consider that the impact of tsunami experience was minimal, given that the contribution demonstrated in previous research [7] was subtle, albeit significant. The negative finding is also somewhat consistent with the mixed results pertaining to the effects of disaster experience on risk perception reported for other types of disasters [46].

Research on factors promoting appropriate tsunami evacuation will require further accumulation of data from future events. Apart from the shortcomings discussed above, the current findings are yet to be generalized over different sociocultural contexts. Longitudinal surveys would provide evidence on causality, which we could only speculate in this study. The international research community should engage in future surveys that maximize shared knowledge and minimize the load on survey participants. This research should involve collaboration with cognitive sciences, including behavioral experiments and neuroscience, to clarify how the contributing factors affect the perception of risk or threat and behavioral decisions [11]. Such knowledge on the psychological processes and mechanisms may inspire new concepts and yield a strategic approach to develop tsunami disaster mitigation measures.

Supplementary Materials: The following are available online at http://www.mdpi.com/2076-3263/9/8/326/s1: Original questionnaire (survey_questionnaire.pdf; Japanese); English translation of the questionnaire items relevant to this study (survey_questionnaire_translations.xlsx).

Author Contributions: Conceptualization of the survey, M.S., S.S., R.N., A.H., T.A., T.M., and F.I.; methodology of the survey, M.S. and S.S.; analysis, M.S., and R.N.; writing, original draft preparation, M.S.; writing, review and editing, M.S., S.S., R.N., A.H., R.I., T.A., T.M., and F.I.

Funding: This research was supported by Special Project Researches (H24-A-5 and H25-A-4) from the International Research Institute of Disaster Science, Tohoku University, Topic-Setting Program to Advance Cutting-Edge Humanities and Social Sciences Research, and KAKENHI 17H06219 from the Japan Society for the Promotion of Science.

Conflicts of Interest: The authors declare no conflict of interest. The funders had no role in the design of the study or in the collection, analyses, or interpretation of the data; in the writing of the manuscript; nor in the decision to publish the results. 


\section{References}

1. Dudley, W.C.; Whitney, R.; Faasisila, J.; Fonolua, S.; Jowitt, A.; Chan-Kau, M. Learning from the victims: New physical and social science information about tsunamis from victims of the September 29, 2009 event in Samoa and American Samoa. Earth-Sci. Rev. 2011, 107, 201-206. [CrossRef]

2. Esteban, M.; Tsimopoulou, V.; Mikami, T.; Yun, N.Y.; Suppasri, A.; Shibayama, T. Recent tsunamis events and preparedness: Development of tsunami awareness in Indonesia, Chile and Japan. Int. J. Disaster Risk Reduct. 2013, 5, 84-97. [CrossRef]

3. Gaillard, J.C.; Clavé, E.; Vibert, O.; Denain, J.C.; Efendi, Y.; Grancher, D.; Liamzon, C.C.; Sari, D.R.; Setiawan, R. Ethnic groups' response to the 26 December 2004 earthquake and tsunami in Aceh, Indonesia. Nat. Hazards 2008, 47, 17-38. [CrossRef]

4. Gregg, C.E.; Houghton, B.F.; Paton, D.; Lachman, R.; Lachman, J.; Johnston, D.M.; Wongbusarakum, S. Natural Warning Signs of Tsunamis: Human Sensory Experience and Response to the 2004 Great Sumatra Earthquake and Tsunami in Thailand. Earthq. Spectra 2006, 22, S671-S691. [CrossRef]

5. Iemura, H.; Takahashi, Y.; Harris Pradono, M.; Sukamdo, P.; Kurniawan, R. Earthquake and tsunami questionnaires in Banda Aceh and surrounding areas. Disaster Prev. Manag. Int. J. 2006, 15, 21-30. [CrossRef]

6. Lindell, M.K.; Prater, C.S.; Gregg, C.E.; Apatu, E.J.I.; Huang, S.-K.; Wu, H.C. Households' immediate responses to the 2009 American Samoa Earthquake and Tsunami. Int. J. Disaster Risk Reduct. 2015, 12, 328-340. [CrossRef]

7. Lachman, R.; Tatsuoka, M.; Bonk, W.J. Human behavior during the tsunami of May 1960. Science 1961, 133, 1405-1409. [CrossRef]

8. Central Disaster Management Council. From the 7th meeting of the Committee for Technical Investigation on Countermeasures for Earthquakes and Tsunamis Based on the Lessons Learned from the 2011 off the Pacific coast of Tohoku Earthquake; Cabinet Office, Government of Japan: Tokyo, Japan, 2011.

9. Cabinet Office. White Paper on Disaster Management 2011, Executive Summary (Provisional Translation). Government of Japan: Tokyo, Japan, 2011.

10. Suppasri, A.; Shuto, N.; Imamura, F.; Koshimura, S.; Mas, E.; Yalciner, A.C. Lessons learned from the 2011 Great East Japan tsunami: Performance of tsunami countermeasures, coastal buildings, and tsunami evacuation in Japan. Pure Appl. Geophys. 2013, 170, 993-1018. [CrossRef]

11. Dash, N.; Gladwin, H. Evacuation decision making and behavioral responses: Individual and household. Nat. Hazards Rev. 2007, 8, 69-77. [CrossRef]

12. Lindell, M.K.; Perry, R.W. The protective action decision model: Theoretical modifications and additional evidence. Risk Anal. 2012, 32, 616-632. [CrossRef]

13. Dooley, D.; Catalano, R.; Mishra, S.; Serxner, S. Earthquake Preparedness: Predictors in a Community Survey. J. Appl. Soc. Psychol. 1992, 22, 451-470. [CrossRef]

14. Miceli, R.; Sotgiu, I.; Settanni, M. Disaster preparedness and perception of flood risk: A study in an alpine valley in Italy. J. Environ. Psychol. 2008, 28, 164-173. [CrossRef]

15. Weinstein, N.D.; Lyon, J.E.; Rothman, A.J.; Cuite, C.L. Preoccupation and affect as predictors of protective action following natural disaster. Br. J. Health Psychol. 2000, 5, 351-363. [CrossRef]

16. Yun, N.Y.; Hamada, M. Evacuation Behavior and Fatality Rate during the 2011 Tohoku-Oki Earthquake and Tsunami. Earthq. Spectra 2015, 31, 1237-1265. [CrossRef]

17. Nakaya, N.; Nemoto, H.; Yi, C.; Sato, A.; Shingu, K.; Shoji, T.; Sato, S.; Tsuchiya, N.; Nakamura, T.; Narita, A.; et al. Effect of tsunami drill experience on evacuation behavior after the onset of the Great East Japan Earthquake. Int. J. Disaster Risk Reduc. 2018, 28, 206-213. [CrossRef]

18. Siebert, A. Survivor Personality: Why Some People Are Stronger, Smarter, and More Skillful at Handling Life's Diffi culties... and How You Can Be, Too; Penguin: London, UK, 2010.

19. Rotter, J.B. Generalized expectancies for internal versus external control of reinforcement. Psychol. Monogr. Gen. Appl. 1966, 80, 1-28. [CrossRef]

20. Sattler, D.N.; Kaiser, C.F.; Hittner, J.B. Disaster Preparedness: Relationships Among Prior Experience, Personal Characteristics, and Distress. J. Appl. Soc. Psychol. 2000, 30, 1396-1420. [CrossRef]

21. Sims, J.H.; Baumann, D.D. The Tornado Threat: Coping Styles of the North and South. Science 1972, 176, 1386-1392. [CrossRef] 
22. Chauvin, B.; Hermand, D.; Mullet, E. Risk Perception and Personality Facets. Risk Anal. 2007, 27, 171-185. [CrossRef]

23. Sugiura, M.; Sato, S.; Nouchi, R.; Honda, A.; Abe, T.; Muramoto, T.; Imamura, F. Eight personal characteristics associated with the power to live with disasters as indicated by survivors of the 2011 Great East Japan Earthquake disaster. PLoS ONE 2015, 10, e0130349. [CrossRef]

24. Brun, W. Cognitive components in risk perception: Natural versus manmade risks. J. Behav. Decis. Mak. 1992, 5, 117-132. [CrossRef]

25. Slovic, P. Perception of risk. Science 1987, 236, 280-285. [CrossRef] [PubMed]

26. Gierlach, E.; Belsher, B.E.; Beutler, L.E. Cross-Cultural Differences in Risk Perceptions of Disasters. Risk Anal. 2010, 30, 1539-1549. [CrossRef] [PubMed]

27. Renn, O.; Rohrmann, B. Cross-Cultural Risk Perception: State and Challenges. In Cross-Cultural Risk Perception: A Survey of Empirical Studies; Renn, O., Rohrmann, B., Eds.; Springer: Boston, MA, USA, 2000; pp. 211-233.

28. Kasperson, R.E.; Renn, O.; Slovic, P.; Brown, H.S.; Emel, J.; Goble, R.; Kasperson, J.X.; Ratick, S. The Social Amplification of Risk: A Conceptual Framework. Risk Anal. 1988, 8, 177-187. [CrossRef]

29. Renn, O.; Burns, W.J.; Kasperson, J.X.; Kasperson, R.E.; Slovic, P. The Social Amplification of Risk: Theoretical Foundations and Empirical Applications. J. Soc. Issues 1992, 48, 137-160. [CrossRef]

30. Miles, B.; Morse, S. The role of news media in natural disaster risk and recovery. Ecol. Econ. 2007, 63, 365-373. [CrossRef]

31. Oki, S.; Nakayachi, K. Paradoxical effects of the record-high tsunamis caused by the 2011 Tohoku earthquake on public judgments of danger. Int. J. Disaster Risk Reduct. 2012, 2, 37-45. [CrossRef]

32. Västfjäll, D.; Peters, E.; Slovic, P. Affect, Risk Perception and Future Optimism after the Tsunami Disaster. Judgm. Decis. Mak. 2008, 3, 64-72.

33. Antronico, L.; Coscarelli, R.; De Pascale, F.; Condino, F. Social Perception of Geo-Hydrological Risk in the Context of Urban Disaster Risk Reduction: A Comparison between Experts and Population in an Area of Southern Italy. Sustainability 2019, 11, 2061. [CrossRef]

34. Grothmann, T.; Reusswig, F. People at Risk of Flooding: Why Some Residents Take Precautionary Action While Others Do Not. Nat. Hazards 2006, 38, 101-120. [CrossRef]

35. Paton, D.; Johnston, D. Disasters and communities: vulnerability, resilience and preparedness. Disaster Prev. Manag. 2001, 10, 270-277. [CrossRef]

36. Global Assessment Report on Disaster Risk Reduction; United Nations Office for Disaster Risk Reduction (UNDRR): Geneva, Switzerland, 2019.

37. Drabek, T.E. Attitudes toward and the Adoption of Adjustments. In Human System Responses to Disaster: An Inventory of Sociological Findings; Springer New York: New York, NY, USA, 1986; pp. 348-405.

38. Helweg-Larsen, M. (The Lack of) Optimistic Biases in Response to the 1994 Northridge Earthquake: The Role of Personal Experience. Basic. Appl. Soc. Psychol. 1999, 21, 119-129. [CrossRef]

39. Spittal, M.J.; McClure, J.; Siegert, R.J.; Walkey, F.H. Optimistic bias in relation to preparedness for earthquakes. Australas. J. Disaster Trauma Stud. 2005, 2005-1. Available online: https://www.massey.ac.nz/ \{\}trauma/issues/ 2005-1/spittal.htm (accessed on 24 July 2019).

40. Taylor, S.E.; Brown, J.D. Illusion and well-being: A social psychological perspective on mental health. Psychol. Bull. 1988, 103, 193-210. [CrossRef] [PubMed]

41. Darvill, T.J.; Johnson, R.C. Optimism and Perceived Control of Life Events as Related to Personality. Personal. Individ. Differ. 1991, 12, 951-954. [CrossRef]

42. Sharot, T.; Riccardi, A.M.; Raio, C.M.; Phelps, E.A. Neural mechanisms mediating optimism bias. Nature 2007, 450, 102. [CrossRef] [PubMed]

43. Hall, T.E.; Slothower, M. Cognitive factors affecting homeowners' reactions to defensible space in the Oregon Coast Range. Soc. Nat. Resour. 2009, 22, 95-110. [CrossRef]

44. Mileti, D.S.; O’Brien, P.W. Warnings During Disaster: Normalizing Communicated Risk. Soc. Probl. 1992, 39, 40-57. [CrossRef]

45. Scolobig, A.; De Marchi, B.; Borga, M. The missing link between flood risk awareness and preparedness: Findings from case studies in an Alpine Region. Nat. Hazards 2012, 63, 499-520. [CrossRef]

46. Wachinger, G.; Renn, O.; Begg, C.; Kuhlicke, C. The Risk Perception Paradox-Implications for Governance and Communication of Natural Hazards. Risk Anal. 2013, 33, 1049-1065. [CrossRef] 
47. Fritz, H.M.; Kalligeris, N. Ancestral heritage saves tribes during 1 April 2007 Solomon Islands tsunami. Geophys. Res. Lett. 2008, 35. [CrossRef]

48. Marín, A.; Gelcich, S.; Araya, G.; Olea, G.; Espíndola, M.; Castilla, J.C. The 2010 tsunami in Chile: Devastation and survival of coastal small-scale fishing communities. Mar. Policy 2010, 34, 1381-1384. [CrossRef]

49. Statistics Bureau, Ministry of Internal, Japan. Disaster related data for the Pacific Coast of East Japan (Japanese); 2013. Available online: http://www.stat.go.jp/info/shinsai/zuhyou/data0917.xls (accessed on 24 July 2019).

50. Gosling, S.D.; Rentfrow, P.J.; Swann, W.B., Jr. A very brief measure of the Big-Five personality domains. J. Res. Personal. 2003, 37, 504-528. [CrossRef]

51. Oshio, A.; Shingo, A.; Cutrone, P. Development, Reliability, and Validity of the Japanese Version of Ten Item Personality Inventory (TIPI-J). Jpn. J. Personal. 2012, 21, 40-52. [CrossRef]

52. Belsley, D.A.; Kuh, E.; Welsch, R.E. Regression Diagnostics: Identifying Influential Data and Sources of Collinearity; John Wiley \& Sons: Hoboken, NJ, USA, 1980.

53. Nagelkerke, N.J.D. A Note on General Definition of the Coefficient of Determination. Biometrika 1991, 78, 691-692. [CrossRef]

54. Bateman, J.M.; Edwards, B. Gender and Evacuation: A Closer Look at Why Women Are More Likely to Evacuate for Hurricanes. Nat. Hazards Rev. 2002, 3, 107-117. [CrossRef]

55. Anderson, C.R.; Schneier, C.E. Locus of Control, Leader Behavior and Leader Performance Among Management Students. Acad. Manag. J. 1978, 21, 690-698. [CrossRef]

56. Dumitriu, C.; Timofti, I.C.; Nechita, E.; Dumitriu, G. The Influence of the Locus of Control and Decision-making Capacity upon the Leadership Style. Procedia Soc. Behav. Sci. 2014, 141, 494-499. [CrossRef]

57. Helmer, S.M.; Krämer, A.; Mikolajczyk, R.T. Health-related locus of control and health behaviour among university students in North Rhine Westphalia, Germany. BMC Res. Notes 2012, 5, 703. [CrossRef]

58. Wallston, K.A. Hocus-pocus, the focus isn't strictly on locus: Rotter's social learning theory modified for health. Cogn. Ther. Res. 1992, 16, 183-199. [CrossRef]

59. Rotter, J.B. Some problems and misconceptions related to the construct of internal versus external control of reinforcement. J. Consult. Clin. Psychol. 1975, 43, 56-67. [CrossRef]

60. McCrae, R.R.; Costa, P.T., Jr. Personality, coping, and coping effectiveness in an adult sample. J. Personal. 1986, 54, 385-404. [CrossRef]

61. Watson, D.; Hubbard, B. Adaptational Style and Dispositional Structure: Coping in the Context of the Five-Factor Model. J. Personal. 1996, 64, 737-774. [CrossRef]

62. Hattrup, K.; O'Connell, M.S.; Labrador, J.R. Incremental Validity of Locus of Control After Controlling for Cognitive Ability and Conscientiousness. J. Bus. Psychol. 2005, 19, 461-481. [CrossRef]

63. Organ, D.W. Extraversion, locus of control, and individual differences in conditionability in organizations. J. Appl. Psychol. 1975, 60, 401-404. [CrossRef] [PubMed]

64. Jang, K.L.; Livesley, W.J.; Angleitner, A.; Riemann, R.; Vernon, P.A. Genetic and environmental influences on the covariance of facets defining the domains of the five-factor model of personality. Personal. Individ. Differ. 2002, 33, 83-101. [CrossRef]

65. Tedeschi, R.G.; Calhoun, L.G. The Posttraumatic Growth Inventory: Measuring the positive legacy of trauma. J. Trauma. Stress 1996, 9, 455-471. [CrossRef] [PubMed]

(C) 2019 by the authors. Licensee MDPI, Basel, Switzerland. This article is an open access article distributed under the terms and conditions of the Creative Commons Attribution (CC BY) license (http://creativecommons.org/licenses/by/4.0/). 